\title{
Una aproximación jurisprudencial al problema de los límites materiales de la negociación colectiva en el ámbito de la función pública de las corporaciones locales
}

\author{
Nuria Garrido Cuenca \\ Facultad de Derecho de Albacete
}

(Comentario a la Sentencia 240/90 de 11 de abril del Tribunal Superior de Justicia de Castilla-La Mancha)

\section{INTRODUCCION}

La Sentencia objeto de este comentario versa sobre uno de los capítulos más controvertidos y polémicos de nuestra Función Pública actual: la negociación colectiva ${ }^{1}$.

Partiendo del reconocimiento de esta institución en nuestra Función Pública, la Sala profundiza en dos temas que inciden directamente en el principal, siendo éstos la base jurídica de apoyo a la resolución del recurso, en concreto los ya considerados dogmas tradicionales en esta materia: naturaleza estatutaria de la relación funcionarial, el mismo concepto de Estatuto de los funcionarios, y el significado de la reserva de ley prevista en el art. 103.3 de la Constitución. Después, y descendiendo de lo general a lo particular, va analizando concretamente los contenidos del Convenio sometidos a su consideración.

A la vista de estos antecedentes, nuestra exposición intentará seguir el método deductivo empleado en la Sentencia, abundando en los temas debatidos a la luz del marco plurinormativo que encuadra el ámbito de las relaciones colectivas funcionariales y de las posiciones doctrinales vertidas al respecto, no sin antes rememorar, siquiera a grandes rasgos, el proceso hacia la Negociación Colectiva de los funcionarios.

\footnotetext{
${ }^{1}$ La decisión judicial en cuestión, resuelve el recurso contencioso-administrativo seguido a instancia de la Administración del Estado frente al Ayuntamiento de Albacete, sobre el Convenio Colectivo con su funcionariado y personal laboral, aprobado por el Pleno de la Corporación el 22 de marzo de 1989.
} 
Las materias concretas del Convenio Colectivo que son impugnadas son las que siguen:

- Derecho de reducción de jornada: se reconoce a los funcionarios con hijos menores de 10 años ${ }^{2}$.

- Vacaciones: se establece una ampliación de las mismas en razón a los años de servicio, desde 5 días para funcionarios que sobrepasen 40 años de servicio, hasta un día más a los que sobrepasen los 20 años ${ }^{3}$.

- Permisos: señala 9 días de vacaciones al año retribuidas para asuntos propios ${ }^{4}$.

- Incentivos a las jubilaciones: que oscilan de 750.000 pesetas para los funcionarios que soliciten la jubilación a los 60 años a 200.000 para los que se jubilen a los 645 .

-Retribuciones: por un lado se prevé un incremento bruto global de la masa salarial en un 5'7\% 6; por otro se escinde el complemento de productividad en tres tipos, para una mejor organización y adecuación a la realidad propia de la Corporación Municipal 7.

Expuesto en sus puntos más controvertidos el Convenio, sinteticemos las posiciones de las partes. Por un lado, la Administración del Estado

2 El art. 30 Ley 30/84, de 2 de agosto, de Medidas para la reforma de la Función Pública (LMFP), lo reconoce sólo a funcionarios con hijos de hasta 6 años.

3 El Reglamento de Funcionarios de la Administración Local en su art. 46.1 establece un periodo de un mes de vacaciones.

${ }^{4}$ La Instrucción de la Secretaría de Estado para la Administración Pública de 21 de diciembre de 1983 concede 6 días por este concepto.

$5 \mathrm{El}$ art. 139. 1. c) del RD 781/86 de 18 de abril, Texto refundido de las disposiciones legales vigentes en materia de Régimen Local, simplemente permite la jubilación a los 60 años, siempre que se hayan cumplido 30 años en servicio activo, remitiendo en tal caso al régimen general de pensiones.

6 El art. 25 de la ley $37 / 88$ de 28 de diciembre de Presupuestos generales del Estado, autoriza un máximo incremento del $4 \%$ en las retribuciones básicas y complementarias.

${ }^{7} \mathrm{El}$ art. 23.3 LMFP y el art. 27.1 e) de la ley de Presupuestos, establecen la fijación individualizada del complemento en concepto de retribución a determinados funcionarios por su especial rendimiento, actividad extraordinaria e iniciativa con que el funcionario desempeñe su trabajo. 
JURISPRUDENCIA

entiende que su contenido excede el ámbito de la negociación colectiva propio de la naturaleza de la relación funcionarial al derogar normas imperativas, en lo que se aparta de la regulación vigente, en unos casos, y en otros, al invadir competencias legislativas. Por su parte, el Letrado municipal defiende la posibilidad del pacto en todo aquéllo que no tenga carácter imperativo, y la licitud de introducir variaciones y mejoras en los aspectos que no atenten al espíritu de la norma estatal ${ }^{8}$, señalando lo absurdo que resultaría limitar el ámbito de la negociación únicamente a los aspectos no abarcados por normas estatales, ya que al ser ésta una materia regulada por entero en todos sus extremos, aquéllo supondría una negación de facto de la negociación.

\section{UNA APROXIMACION HISTORICA AL SIGNIFICADO DE LA NEGOCIACION COLECTIVA EN LA FUNCION PUBLICA}

Aunque el objetivo de estas líneas no sea ofrecer una visión histórica del tema ${ }^{9}$, parece a todas luces conveniente describir, siquiera sucintamente, como punto de partida para la compresión del actual estado de la cuestión, cuál ha sido el proceso hacia la negociación colectiva funcionarial. Y ello, teniendo presente la innegable relación existente entre el mismo devenir del Estado, la lógica político-económica que preside cada momento histórico, y la propia dinámica sociológica propiciada por el fenómeno administrativo como tal 10.

Comenzaremos así por señalar el reflejo que ha producido en la Función Pública el cambio operado en el concepto del propio Estado ${ }^{11}$.

\footnotetext{
${ }^{8}$ En este punto, el Tribunal Superior, aunque con significantes matizaciones, se suma a la postura mantenida por el Ayuntamiento, como posteriormente veremos.

9 Para ello, vid. por todos, Luis ORTEGA, Los derechos sindicales de los funcionarios publicos, Tecnos, Madrid, 1983; DEL REY GUANTER, Estado, Sindicatos y relaciones colectivas en la Función Pública, INAP, Madrid, 1986 y R. PARADA, Sindicatos y Asociaciones de Funcionarios Públicos, Tecnos, Madrid, 1986.

10 Esta interrelación parece ser el fondo que subyace en la explicación del mecanismo negocial, y así lo han anotado especialmente, SANCHEZ MORON, M. en su trabajo "Notas sobre la Función administrativa en la Constitución española de 1978", inserto en el libro colectivo La Constitución española de 1978, Estudio Sistemático dirigido por los Prof. GARCIA DE ENTERRIA y PREDIERI, Civitas, Madrid, 1984, pp. 627 y ss. y ORTEGA ALVAREZ, op. cit., pp. 31 y ss.

11 La necesidad de comenzar cualquier estudio referido a la Función Pública con su entronque histórico-político, en lo que coincide la mayoría de la doctrina, queda especialmente patente en el Tratado del prof. FUERTES SUAREZ, Función Pública, Reforma Administrativa y Estado Autonómico, Civitas, Madrid, 1980, pp. 57 y ss.
} 
En el marco del Estado autoritario, donde se alza la primera teoría en torno a la naturaleza de la relación jurídica funcionarial, conocida como "Tesis Unilateralista", se considera que tal vínculo surge de la voluntad unilateralmente prestada por la Administración 12. En este modelo normativo y teórico, el funcionario es un elemento más de la organización administrativa, el personal, en un esquema donde prima con mucho la relación orgánica sobre la de servicio. Esta relación se somete al Derecho Administrativo, que establece un régimen estatutario y da a la organización administrativa una impronta de jerarquización, estratificación y formalización. En definitiva, y como bien describe Von Potobski 13, la relación estatutaria supone a la vez un freno frente a las posibles reivindicaciones del funcionario y una protección contra las arbitrariedades del Estado: «las buenas condiciones del empleo en la Función Pública están a nivel de la devoción que se le exige en el cumplimiento de sus tareas; se le identifica con el Estado, como su órgano para alcanzar el interés general, que se confunde con el interés del propio funcionario" 14 .

Este modelo tradicional pervivirá incuestionado hasta bien entrado el presente siglo, que se caracterizará por una irreversible mutación de los presupuestos de la tópica trilogía Estado-Economía-Sociedad, y que supone, en definitiva, la crisis del modelo de poder autoritario y del sistema económico liberal.

De modo paralelo a la implantación de la sociedad industrial y la introducción del Estado intervencionista en nuevos campos, se produce una transformación progresiva de las condiciones sociales de los funcionarios: la expansión y diversificación de la pirámide burocrática irá

12 El origen de esta corriente lo encontramos en la conocida obra de HEGEL «La filosofía del derecho»; para él, el fundamento del Estado es la fuerza, y la base del Derecho Público es la posición de supremacía total del poder público respecto al súbdito. El servidor estatal se debe ceñir al cumplimiento de su deber, olvidando su esfera subjetiva e identificándose con el órgano en que trabaja, dando así satisfacción al ente supremo de la colectividad al que está subordinado, el Estado.

13 VON POTOBSKY, "Negociación colectiva en la Administración Pública central y descentralizada», Revista Española del Derecho del Trabajo (REDT), n. ${ }^{\circ} 40,1989$.

14 Para un más completa compresión de esta tesis nos remitimos a la elaboración sobre los postulados básicos de defensa de la teoría estatutaria que enumera ORTEGA ALVAREZ, op. cit., p. 29 y ss. Estos son: imposibilidad de acuerdo contractual debido a la desigual posición jurídica de las voluntades en juego (la pública y la privada), incomerciabilidad del objeto del contrato, regulación mediante ley del contenido de la relación de empleo público, posición de supremacía de la Administración una vez iniciada la relación jurídica, retroactividad de los efectos del contrato al momento del acto de nombramiento. 
JURISPRUDENCLA

haciendo cada vez mayores las distancias entre las categorías funcionariales, se experimenta un empeoramiento relativo de las condiciones de empleo en el sector público frente al ascenso del sector privado. En este sentido, también se empieza a reconocer que el interés del funcionario puede contraponerse al del Estado empleador, e incluso no coincidir con el interés general - que la mayoría de las veces no es sino expresión mimética del de las clases o grupos sociales y económicos dominantes o definición que de él hacen los programas políticos sectoriales-. En fin, la superación del concepto de Estado autoritario en favor de un Estado democrático, supone que el individuo tiene reconocidos un catálogo de derechos y garantías, incluso frente al propio Estado, que éste debe salvaguardar y favorecer ${ }^{15}$.

En este contexto, no es de extrañar la aparición de un movimiento sindical, que se va a ver jurídicamente consolidado con el reconocimiento, sin excepción, de un derecho de sindicación de alcance general en las Constituciones surgidas tras la segunda contienda mundial y que aun con hondos recelos irá incluyendo, en un iter progresivo, a los funcionarios públicos, hasta el punto de convertirse en un corto espacio de tiempo en la categoría más sindicalizada de la Europa Occidental. Ha llegado el momento de que la doctrina unilateralista y estatutaria abra paso a otra, contractualista y participacionista, en la regulación de la situación del funcionario. Así, en la década de los setenta ya es innegable el reconocimiento de estos relevantes derechos sindicales, que suponen la admisión de una contraposición de intereses entre la Administración y sus funcionarios, dejando éstos de identificarse en todo caso con la organización-Administración en que están insertos para pasar a exponer frente a la misma sus lícitas reivindicaciones. En el plano individual, la relación orgánica y la de servicio se superponen, y en el plano supraindividual los intereses funcionariales se conforman como intereses colectivos. En este estado de cosas, la regulación de la negociación y de las formas de participación para la determinación de las condiciones de trabajo de los funcionarios que dé cauce a la defensa y promoción de sus intereses es un fenómeno ya inevitable. Pero recordemos -y ello es algo que no nos puede pasar desapercibido en ningún momento- que ese camino hacia la negociación ha encontrado y sigue tropezando con insoslayables escollos dogmáticos, constitucionales, administrativos y prácticos.

De tal forma, el modelo instaurado en España es una negociación colectiva con intervenciones, limitaciones y condicionamientos, diversa y

15 Una exposición más detallada de los factores que propician el cambio de situación, vid. CARRERA ORTIZ, C., "Naturaleza y eficacia jurídica de la negociación colectiva en la Función Pública en España», REDT, n. ${ }^{\circ} 38,1989$, p. 265. 
de menor alcance que la negociación laboral, reflejo cierto de las precauciones y resistencias del poder público ante un fenómeno tendencialmente expansivo que conlleva una ampliación de poder y espacio de acción de los Sindicatos frente al poder político. Pero en cualquier caso, el reconocimiento de los derechos sindicales en la Función pública, y en especial de la negociación colectiva, ha permitido el paso desde un régimen estatutario de definición unilateral, a un régimen estatutario abierto a la negociación.

En síntesis y para concluir, la negociación colectiva funcionarial significa históricamente el retroceso del principio autoritario en la Administración Pública, y el avance hacia «un marco más democrático y participativo de la relación entre los funcionarios y la Administración, correlativo a una ampliación de los derechos subjetivos individuales y colectivos de los empleados públicos y de su autonomía contractual, que ha facilitado, en fin, la manifestación de una conflictividad que permanecía latente desde mucho tiempo atrás».16.

\section{CRITERIOS DE DELIMITACION MATERIAL DEL AMBITO DE LA NEGOCIACION COLECTIVA EN EL SENO DE LA FUNCION PUBLICA LOCAL SENTADOS POR EL TRIBUNAL SUPERIOR}

Como veremos, el problema a que se enfrenta el Tribunal Superior en esta Sentencia es la delimitación del ámbito material en el que ha de moverse la negociación colectiva en el marco de la Administración Local, ya que a la luz de las recientes reformas legales la posibilidad de acuerdo entre empleador y empleados, como fórmula para la fijación de las condiciones de trabajo en la Función Pública, resulta incuestionable en nuestro ordenamiento ${ }^{17}$. No obstante, el Tribunal matiza esta premisa al considerar, de otra parte, que el funcionario se encuentra sometido a una situación estatutaria, legal y reglamentaria: «el reconocimiento de la negociación colectiva no puede suponer la quiebra o ruptura total de la tesis estatutaria, pero sí la creación de un espacio de regulación conjunta». Este par de principios lleva al Tribunal a admitir una doble situación

16 CARRERA ORTIZ, op. cit., REDT, n. ${ }^{\circ} 38,1989$.

17 En concreto, nos referimos a los siguientes textos legales: Ley Orgánica de Libertad Sindical (art. 2.2.d), Ley 7/85 de 2 de abril de Bases del Régimen Local (art. 95), Ley de Medidas de la Función Pública (art. 3.2.b), Ley 9/87 de 12 de junio, de órganos de representación, determinación de las condiciones de trabajo, y participación del personal al servicio de las Administraciones Públicas. A ellos debemos sumar la Ley 7/90, de 19 de julio, sobre Negociación Colectiva y Participación en las condiciones de trabajo de los empleados públicos - aunque esta ley no fue de aplicación al concreto supuesto estudiado en la Sentencia, por ser posterior su promulgación-. 
JURISPRUDENCIA

en el régimen jurídico funcionarial: estatutaria, en tanto en cuanto gran parte de sus elementos van a estar definidos unilateralmente por la ley y sus reglamentos ejecutivos, y convencional por otra, encuadrando aquellos elementos susceptibles de ser definidos de manera negociada. El debate, por tanto, no es dogmático, sino de orden práctico: determinar el espacio material que puede ocupar la negociación colectiva.

Anticiparemos que, tras una prolija concatenación de conceptos y premisas, el Tribunal Superior llega a una definición negativa del campo de la negociación, en dos grados, construyéndose así un sencillo bisturí para extraer del convenio estipulaciones espúreas:

$1{ }^{\circ}$ Exclusión absoluta de aquellas materias reguladas por el Estado con carácter de legislación básica, ex art. 149.1.18 C.E.

2. ${ }^{\circ}$ Exclusión relativa de aquellas otras sobre las que rige la reserva de ley del art. 103.3 C.E., en el sentido de que aquí la regulación legal opera como mínimo de derecho necesario, mejorable a través de la negociación.

En consecuencia, dentro de estos límites, cualquier aspecto relativo al régimen funcionarial local es materia negociable.

Analicemos los pasos que da el Tribunal para llegar a esta conclusión.

\section{a) Indisponibilidad de la Administración sobre las materias so- metidas a reserva de ley}

A tenor de los arts. 32 a 34 de la Ley 9/87, el Tribunal considera que el ámbito de la negociación encuentra un primer límite infranqueable en las materias sometidas a reserva de ley, por ser éstas indisponibles para la Administración:

«Podría pensarse, por la remisión que efectúa el art. 32 a la negociación, que estamos ante una remisión en bloque e incondicionada de las distintas materias; sin embargo no puede olvidarse el contenido de los arts. 33 y 34 de la referida ley, que vienen a excluir del ámbito de la negociación las materias reservadas a la ley o que supongan incremento de disponibilidades presupuestarias cuya autorización corresponda a las Cortes Generales o Asambleas legislativas de las Comunidades Autónomas, introduciéndolas en el ámbito de la consulta, y a delimitar negativamente el ámbito de la participación. Una interpretación conjunta de estos preceptos obliga a sentar que no todos los aspectos de las materias contempladas en el art.32 pueden quedar por 
completo en manos de los negociadores, ya que la reserva de ley va a condicionar todo el artículo, por lo que el ámbito negocial no podrá afectar a materias regidas por leyes o reglamentos ejecutivos de leyes, siendo preciso distinguir entre aspectos reservados a la ley, de aquéllos que no lo están; en los reservados, no es posible admitir la negociación, porque la Administración no tiene disponibilidad sobre los mismos; en cambio, en los aspectos no reservados a la ley de las materias del art. 32, sí será posible la negociación, dado que la Administración detenta competencia para regularlos, y de ahí que el art. 32 comience estableciendo que "serán objeto de negociación en su ámbito respectivo y en relación con las competencias de cada Administración Pública, las siguientes materias...» (FJ 4).

\section{b) Elementos definitorios del concepto de estatuto funcionarial sobre los que opera la reserva de ley}

Tal y como constata el Tribunal, la Constitución no define el concepto de estatuto de la Función Pública, ni delimita el contenido de su régimen jurídico, a pesar de que sí establece una clara reserva de ley sobre el mismo en el art. 103.3 C.E. Al respecto, el Tribunal se atiene a lo declarado en sede constitucional:

"Si bien el régimen estatutario de los funcionarios públicos es un ámbito cuyos contornos no pueden definirse en abstracto y a priori, sin embargo, en él ha de entenderse comprendida, en principio, la normativa relativa a la adquisición y pérdida de la condición de funcionario, a las condiciones de promoción en la carrera administrativa y a las situaciones que en ésta puedan darse, a los derechos y deberes de los funcionarios y a su régimen disciplinario, a la creación e integración de cuerpos y escalas funcionariales y al modo de provisión de puestos de trabajo al servicio de las Administraciones Públicas..., habrá de ser también la ley la que determine en qué casos y con qué condiciones pueden reconocerse otras posibles vías para el acceso al servicio de las Administraciones Públicas». (STC 99/87 de 11 de junio).

c) Concepción material del estatuto de la Función Pública: integración en el mismo de los preceptos básicos del régimen local

Por otra parte, y desde una perspectiva formal, el Tribunal Constitucional ha admitido en su Sentencia de 25 de junio de 1985, —continúa el Tribunal-, que el estatuto de los funcionarios no ha de establecerse necesariamente en una sola ley, sino que el mismo puede ser fruto de 
JURISPRUDENCIA

regulaciones parciales desarrolladas por diferentes normas legales. En este sentido, y por lo que respecta a la Función Pública local, la Sala nota que habrán de ser tenidos en cuenta de modo especial el Título VII de la Ley de Bases del Régimen Local, «auténtico estatuto del funcionariado local», y las disposiciones básicas del Texto Refundido del Régimen local, así como cualesquiera otros preceptos básicos contenidos en otras leyes «que por considerarse bases del régimen estatutario de los funcionarios, son de aplicación a todas las Administraciones públicas y, en consecuencia, a la local». (FJ 6).

$\mathrm{Al}$ respecto, recuerda que los arts. 5. c y 92 de la propia LBRL establecen que los funcionarios al servicio de la Administración local se rigen, en lo no dispuesto por la misma, por la legislación del Estado y de las Comunidades Autónomas, en los términos del art. 149.1.18 C.E. ${ }^{18}$.

\section{d) Necesidad de que el legislador se autolimite al regular el Esta-} tuto de la Función Pública para abrir espacios a la negociación

Pero según el Tribunal, si se diera carácter absoluto a la reserva de ley impuesta sobre la regulación de la Función Pública a través del estatuto, el art. 32 de la Ley 9/87 carecería de sentido. Para conciliar esta reserva de ley con la necesidad de encontrar un ámbito para la negociación, el Tribunal propone que el legislador deberá autolimitarse.

"Aunque el Estatuto represente el régimen jurídico funcionarial, dicha regulación no tiene porqué ser exhaustiva, y el propio Estatuto puede dejar un espacio sin cubrir, como en el ámbito laboral, remitiendo su determinación a la negociación entre las partes, a la que ha de corresponder una competencia más de detalle de puntos abordados legalmente o de ordenación de cuestiones no tratadas por la ley, aunque siempre, en uno y otro caso, con respeto absoluto a lo regulado por la Ley» (FJ 7).

\section{e) La reserva de ley como forma de tutela de los derechos de los funcionarios frente al poder ejecutivo, un mínimo cogente susceptible de mejora mediante negociación.}

Por último, el Tribunal considera que, en determinados casos, la reserva de ley debe interpretarse «como una forma de tutela de los derechos

\footnotetext{
18 Hemos de apuntar aquí que la Comunidad de Castilla-La Mancha, carece de competencias para desarrollar una legislación propia en materia de funcionarios al servicio de las Corporaciones Locales, por lo que toda la normativa estatal resulta ser de directa aplicación en esta región.
} 
de los funcionarios frente al poder ejecutivo, operando como mínimo de derecho necesario, por lo que, en los aspectos en que sea posible, por permitirlo el legislador cabe mejorar la regulación estatal» (FJ 7).

\section{EL ANALISIS DEL CONTENIDO MATERIAL DEL CONVENIO}

A partir de estas premisas, la Sala discrimina entre los contenidos del Convenio, admitiendo como negociables una lista de materias por su carácter no básico: reducción de jornada por cuidado de hijos, vacaciones y permisos y la jubilación anticipada. Por el contrario, y a la vista de su carácter básico y el sometimiento a reserva de ley, excluye del ámbito negocial las materias que afecten al régimen retributivo, a saber: las pagas extraordinarias, las retribuciones en la situación de servicios especiales, escisión del complemento de productividad en tres facetas y elevación de las retribuciones por encima del máximo legal.

A la vista de cómo resuelve cada uno de los puntos controvertidos, cabría resumir el razonamiento del Tribunal del siguiente modo: la reserva de ley opera como mínimo de derecho necesario en las materias contenidas en normativa que no sea considerada básica. Estas materias serían susceptibles de mejora por negociación colectiva. A sensu contrario, la reserva de ley es inquebrantable en las materias contenidas en preceptos con carácter de básico, susceptibles de regulación en exclusiva por el Estado, postergando en tal caso cualquier posibilidad de negociación.

Es decir, «los aspectos en que permite el legislador mejorar la regulación estatal» -y por ende, negociables-, quedan reducidos a aquéllos contenidos no comprendidos en la normación básica del régimen estatutario de los funcionarios públicos.

a) Reducción de jornada por cuidado de hijos menores, ampliación de las vacaciones en razón de los años de servicio, y permisos para los denominados asuntos propios.

En estas materias se estima admisible la negociación que haya regulado de forma más favorable para el funcionariado, pues ni el art. 142 del Texto Refundido del Régimen Local ni el art. 30 LMFP tienen el carácter de básicos, según la relación establecida en el art. 1.3 LMFP. Pero además, y aunque el Tribunal no lo haya hecho notar, estimamos que estos supuestos son perfectamente encuadrables en el apdo. e) del art. 32 de la Ley 9/87, que considera objeto de negociación: «...las materias de prestación de servicios... y cuantas afecten a las condiciones 
JURISPRUDENCIA

de trabajo", sin que proceda aplicar las particularidades contenidas en los arts. 33 y 34 de la citada Ley, que podrían llevar a una limitación o exclusión de la capacidad convencional de los funcionarios en la regulación de estos contenidos.

\section{b) Incentivos a la jubilación anticipada}

En relación a la jubilación, el Convenio se limita a estimular el derecho a anticipar voluntariamente, al establecer unos incentivos para los funcionarios que optasen por ella. Y ello, a juicio del Tribunal Superior, es posible a la vista del art. 139.1.a) del Texto Refundido del Régimen Local, que regula la jubilación a instancia del interesado sin señalar requisitos o particularidades en cuanto a la posibilidad de incentivarla.

Además, desde nuestro punto de vista, hemos de tener en cuenta que en este supuesto no es de aplicación el art. 33 LMFP, referido a la jubilación forzosa, que tiene carácter de básico, sin que exista razón alguna para subsumir en este precepto ningún otro supuesto de derecho pasivo más que el expresamente previsto en la norma.

Por tanto, al no encontrarse esta materia contenida en ninguna norma básica, aun estando reglada, se declara susceptible de negociación. En este punto, nada podemos objetar al razonamiento del Tribunal.

\section{c) Percepción íntegra de las pagas extraordinarias durante el cumplimiento del servicio militar.}

En este tema el Tribunal estima que habrá que estar a lo preceptuado en los arts. 140 del Texto Refundido de Régimen Local y 29.1.k) LMFP, que establecen la situación de servicios especiales en que por esta causa se encuentra el funcionario. Al constituir esta materia normativa básica, el Ayuntamiento debe sujetarse al régimen general previsto para esta situación, sin que exista posibilidad de negociar esa percepción de pagas extraordinarias, pues se estaría propiciando un estado de desigualdad respecto a los funcionarios del resto de las Administraciones que debemos excluir de plano, según la solución del Tribunal.

Pero aparte de la vulneración de los preceptos citados que supondría admitir la percepción de esas pagas, debemos hacer notar que las pagas extraordinarias (junto al sueldo y los trienios) se incluyen en el concepto de retribución del art. 23 LMFP, que también tiene carácter de básico, al igual que el art. 27.1.B) de la Ley $37 / 88$ de 28 de diciembre, de Presupuestos Generales del Estado, referido a normas generales 
sobre retribuciones del personal funcionario, que en principio se excluyen del ámbito negocial. No obstante, debemos precisar que el Tribunal podría haber seguido otra linea argumental a la hora de excluir de la negociación este concepto retributivo, remitiéndose a los art. 32 y 33 de la Ley $9 / 87$, que limitan la negociación a la aplicación de las retribuciones, el primero, y el segundo a la única posibilidad de consulta en materias que supongan incremento de disponibilidades presupuestarias (presupuesto éste último en que enmarcaríamos el supuesto que estudiamos).

\section{d) Incremento de las retribuciones}

En relación al incremento retributivo máximo dispuesto en la Ley 37/88 de Presupuestos Generales, el Tribunal estima que el incremento bruto total de la masa salarial sobre las retribuciones de 1988 fijado por el Convenio es superior al $4 \%$ a que hace referencia el art. 25 de la Ley $37 / 88$. A esta afirmación cabría precisar una serie de objeciones importantes, pues a tenor de la misma literalidad del precepto que se considera infringido por el convenio (el art. 25 Ley 37/88), el Tribunal incurre en ciertas confusiones que le llevan, al menos a nuestro juicio, a una tesis un tanto apresurada, cual es la inadmisibilidad de negociación sobre cualquier aspecto del régimen retributivo, incluso negando el contenido del art. 32 a) de la ley 9/87, que permite negociar la "aplicación de las retribuciones».

Tras un análisis exegético del art. 25 de la Ley 37/88, observamos que bajo el concepto de «incremento de las retribuciones del personal al servicio del Sector Público", se subsumen tres supuestos perfectamente diferenciados, según al tipo de personal al servicio de la Administración a que van dirigidos: el régimen retributivo del personal en activo no laboral del Sector público (art. 25.1 y 2), el incremento de la masa salarial del personal laboral (art. 25.3), y el establecimiento de un fondo adicional aplicable por igual a los funcionarios y al personal laboral (Art. 25.4).

Pues bien, el Tribunal parece obviar esta distribución, incurriendo en un primer error al utilizar los conceptos de "retribución" y "masa salarial» indistintamente, cuando el precepto separa dentro del régimen retributivo ambos contenidos ${ }^{19}$. Si además la ley establece distinta regulación en sendos apartados, no nos parece correcto englobar dos regímenes dispares bajo un mismo concepto «incremento bruto total de la masa salarial",

19 Y esto resulta evidente por la misma dicción del párrafo $3 .^{\circ}$ del art. 25.3, que define la masa salarial como "conjunto de las retribuciones salariales y extrasalariales y los gastos de acción social devengados por el personal laboral"; por otra parte, el art. 25.1 se refiere a la "cuantía de las retribuciones del personal en activo del sector público, excepto el sometido a la legislación laboraln. 
término empleado por el Tribunal, y que tras este análisis vemos que no encuentra acomodo legal alguno en el art. 25 de la Ley.

Si bien éste es ya un error que hemos de considerar, más relevante resulta la interpretación excesivamente rígida y restrictiva del significado de "incremento retributivo", que se considera por el Tribunal como límite máximo a respetar en todo caso. Pues, si en principio nada cabe objetar a tal posición en cuanto a su aplicación a las retribuciones básicas, es a todas luces necesario considerar la posible excepción que en relación al conjunto de las retribuciones complementarias sufre ese máximo del $4 \%$ previsto para 1989. El art. 25.1 en sus apdos. a) y b) parece dejar a salvo de ese límite las retribuciones complementarias de carácter fijo y periódico, que experimentarán un incremento del $4 \%$ «sin perjuicio de la adecuación de éstas últimas cuando sea necesario para asegurar que la retribución total de cada puesto de trabajo guarde relación procedente con el contenido de especial dificultad técnica, dedicación, responsabilidad, peligrosidad o penosidad del mismo". Y respecto al conjunto de las demás retribuciones complementarias, se respetará el incremento, "sin perjuicio de las modificaciones que se deriven de la variación del número de efectivos asignados a cada programa, del grado de consecución de los objetivos fijados para el mismo y del resultado individual de su aplicación".

A nuestro juicio, cabría entender que si bien ese incremento de las retribuciones en un $4 \%$ es un tope al que las retribuciones básicas se deben ajustar sin ningún tipo de excepción, en las retribuciones complementarias ese máximo se flexibiliza siempre que concurra alguna de las causas taxativamente previstas en el precepto analizado 20 .

Por todo lo antedicho, compartimos en parte la opinión del Tribunal cuando niega la posibilidad de negociar el incremento de las retribuciones básicas, por ser contenido reservado a la ley, al constituir normativa básica 21 ; pero entendemos que cabría negociar las retribuciones

20 Nos sumamos con esta conclusión a la opinión de la doctrina más autorizada y en concreto de PARADA VAZQUEZ, al afirmar categóricamente que "las retribuciones complementarias no tienen señalado un límite máximo en función de las básicas ni de cualquier otro tipo" PARADA VAZQUEZ, Derecho Administrativo. Organización y empleo público, $3^{\mathrm{a}}$ edición, Marcial Pons, 1989, p. 351.

21 Este sería uno de los supuestos en que la definición de lo básico exige una regulación generalizada y uniforme para todo el conjunto de las Administraciones Locales, pero sólo uno de los supuestos, pues a renglón seguido el Tribunal Constitucional recuerda que «no hay necesariamente una reserva de ley para la normación de lo básico en el art. 149.1.18 C.E.". SSTC 42/81 de 22 de diciembre, 25/83 de 7 de abril y 85/83 de 25 de octubre, entre otras en las que se refleja este juicio. 
complementarias, siempre que concurriera alguna de las causas taxativas del art. 25 de la ley 37/88. Para reforzar nuestra tesis recordemos de nuevo el art. 32 a) de la ley 9/87, que considera objeto de negociación la "aplicación de las retribuciones de los funcionarios", que puesto en conexión con los apdos. a) y b) del art. 25 de la Ley de Presupuestos, nos lleva a la conclusión de que es la aplicación del sistema retributivo la que en definitiva nos precisará la necesidad de adecuación o modificación de las retribuciones complementarias 22.

Y aún es más -y aunque a primera vista pudiera parecer una interpretación forzada en exceso- todavía podríamos esgrimir otro argumento en favor de nuestra tesis, con la mera lectura del art. 25.4 de la Ley de Presupuestos, que establece un fondo adicional de $20.000 \mathrm{mi}$ llones para mejoras retributivas que se apliquen «en función de los Acuerdos o pactos adoptados por los mecanismos de participación sindical previstos en la ley $9 / 87$ respecto a los funcionarios, y respecto del personal laboral, en el marco de la negociación colectiva". A nuestro entender, la misma Ley de Presupuestos parece hacerse eco del nuevo marco normativo de la relación funcionarial tras el reconocimiento de la negociación colectiva en la Función Pública previsto en la Ley $9 / 87$, e intuyendo la pronta aplicación práctica de los mecanismos negociales, reserva ese fondo para dar cabida a posibles incrementos retributivos fruto de la negociación ${ }^{23}$.

\section{e) El complemento de productividad}

En estrecha conexión con el tema que acabamos de exponer, cabría decir algo sobre la supuesta ilegalidad en la regulación del complemento de productividad previsto en el Convenio. Con toda razón, el Tribunal considera nula la escisión de tal concepto retributivo en tres facetas, al desnaturalizar por completo su auténtica esencia, contenido y finalidad, que no es otra que la que expresamente prevé el art. 23.3 c) LMFP: «retribuir el especial rendimiento, la actividad extraordinaria e iniciativa con que el funcionario desempeña su trabajo». En ningún caso sería

\footnotetext{
22 Algo análogo creemos quiere significar el último inciso del art. 25.1.b) de la ley 37/88, que expresamente prevé la posibilidad de «...modificaciones en el crecimiento del $4 \%$ que se deriven... del resultado individual de su aplicación".

23 Una vez más se hacen palpables las injustificadas reservas - cierto recelo, diríamos más bien- de los tribunales a la hora de enjuiciar la admisión sin recatos, en su más amplia extensión, de la capacidad convencional de los funcionarios para la determinación de sus condiciones de trabajo, y sobre todo en un aspecto como el retributivo, que sin dudas, es el que más escama hasta la fecha ha provocado en cuanto a la posible intromisión del servidor público en su delimitación.
} 
JURISPRUDENCIA

ajustado a derecho su aplicación como "complemento nivelador», para compensar la diferencia retributiva íntegra anual ocasionada por un nuevo sistema retributivo, pues en tal caso se estaría identificando, a nuestro juicio, con la funcionalidad del complemento personal y transitorio a que se refiere la Disposición Transitoria $10^{\mathrm{a}}$ de la LMFP y el art. $27.1 \mathrm{~g})$ de la Ley de Presupuestos del 88.

Esto es lo que parece establecer el Convenio, al enmascarar el complemento de productividad bajo una pretensión de mejor organización municipal y adecuación a la realidad propia de la Corporación 24.

No obstante, el Tribunal se muestra de nuevo restrictivo al considerar «excluida toda posible negociación en el ámbito del art. 23 LMFP, que regula entre otras materias el complemento de productividad, por ser éste un precepto básico». Evidentemente, el Convenio no puede especificar o añadir innovaciones en el sistema retributivo previsto en la LMFP, pero ello no implica mutatis mutandi la imposibilidad de incluir un mínimo contenido negociable en la operatividad del precepto. Y con más razón respecto al complemento de productividad, que establecido en una cuantía global en la Ley de Presupuestos del Estado debe ser objeto de reparto, para determinar la cuantía individual que corresponde en cada caso a los funcionarios $i$ Y ello no es encuadrable en el supuesto de "aplicación de las retribuciones", posible contenido material de la negociación colectiva en virtud del art. 32 de la ley 9/87? Si así fuere - hecho éste que a nuestro juicio no ofrece duda alguna-, podríamos concluir afirmando que es incluso la propia técnica presupuestaria la que permite ciertos márgenes de negociación de los contenidos retributivos 25 .

En síntesis, lo que hemos querido significar con nuestro análisis crítico y exhaustivo de los concretos contenidos económicos del Convenio es que el principio de legalidad presupuestaria no impide, en principio, que la determinación de la cuantía de las retribuciones de los funcionarios pueda también ser objeto de negociación. Empero, creemos que si la Ley de Presupuestos se manifestare en sentido contrario, prevalecería

24 Esta técnica de desnaturalización de las retribuciones complementarias, tanto el complemento de productividad como el específico, utilizando tales conceptos como normas de cobertura que amparan verdaderos fraudes de ley, con una pretensión niveladora cara al nuevo sistema retributivo instaurado por la LMFP, es motivo reiterado que ha propiciado una vasta jurisprudencia en nuestro Tribunal Superior. Vid por todas la S. Tribunal Superior de Justicia de Castilla-La Mancha 10/89 de 12 de enero.

25 Con ánimo de no ser excesivamente reiterativos, trasladamos todo lo expuesto supra sobre incrementos retributivos, a este concreto concepto, en cuanto a nuestra tesis sobre la posibilidad de negociación en este tema. 
frente a lo acordado por la vía del procedimiento negocial, y ello en virtud de los principios de jerarquía normativa y primacía de la Ley 26.

Aunque nuestra concepción sobre la negociación colectiva funcionarial, y en especial la ampliación de su alcance material, pudiera parecer imprudente, creo que solo hemos reflejado una realidad cierta que cada vez con más fuerza se manifiesta en el complejo mundo de la burocracia, intentando encontrar cobijo legal a la reivindicación de unos derechos como los sindicales, que tantas veces le han sido vedados.

\section{UNA SENTENCIA MIMETICA Y RESTRICTIVA. UNA CRITICA DESDE LA CONSTITUCION Y LA DOCTRINA}

A nuestro juicio, si bien nada hay que reprochar a la fundamentación jurídica de la Sentencia, no compartimos la técnica empleada para dilucidar el fondo en sí del recurso, al articularse la solución en torno a un único concepto, el de la normativa básica, pareciendo olvidar toda una sólida construcción dogmática precedente.

Es decir, el Tribunal no extrae las consecuencias que cabría esperar del análisis trazado sobre las normas de aplicación al caso en abstracto, deslizándose por el contrario hacia una restrictiva utilización del criterio de reserva material de ley básica.

Y es más, parece que el Tribunal ha preterido que nos enfrentamos ante un tema inmerso en un complejo sistema multinormativo, en el que quizás con más ahínco que en cualquier otro, debemos cohonestar

${ }^{26}$ En este sentido, AVELINO BLASCO se pronuncia sobre el tema partiendo de la posibilidad de dos supuestos:

a) si el convenio se celebra previamente a la aprobación de la Ley de presupuestos, no perdería su carácter contractual por el mero hecho de que la cuantía global del incremento salarial fuese modificada en sede parlamentaria. Esta posibilidad actuaría como una condición suspensiva del convenio válidamente suscrito. En este caso el contenido económico del convenio contribuiría a la formación del Anteproyecto de Ley de Presupuestos - sin perjuicio de que el legislador no esté vinculado por el convenio-.

b) si el convenio se celebra con posteridad a la aprobación de la Ley de Presupuestos, ésta es una norma superior e imperativa, que se impone necesariamente a los convenios celebrados bajo su vigencia; por ello, el convenio que la vulnere incurrirá en ilegalidad y podrá ser anulado. En este supuesto los convenios que se celebren se insertarán en la aplicación y ejecución de la norma presupuestaria.

Vid. BLASCO A., «La negociación colectiva de los funcionarios públicos» REDA, n. 52, 1986. 
campos temáticos diversos. Por un lado, una sistemática interpretación de la Constitución, sin desconocer la indudable trascendencia y relación de todos los preceptos referidos a la Administración y a la Función Pública 27. Por otro lado, una diversa y dispersa regulación normativa específica, un universo de normas en muchos casos heterógeneas y controvertidas. Por fin, una realidad social y coyunturalmente conexa con estos dos planos. Y estos tres niveles hemos de articularlos en aras de conseguir un sistema armónico y coherente.

A la hora de solucionar un conflicto de características similares a las que preocupan a nuestro estudio, no podemos escindir o separarnos de ninguna de estas realidades, peligro que subyace siempre que nos enfrentamos a la controversia que supone el intentar compatibilizar la dualidad de un régimen estatutario - pilar de nuestra función públi$\mathrm{ca}-\mathrm{y}$ el reconocimiento de un margen de autonomía colectiva -ínsito en el art. 28 C.E.- del que goza todo funcionario.

Por todo lo anterior, llegamos a la conclusión de que, si bien en materia de función pública local hay que tomar en cuenta el art. 149.1.18, que atribuye al Estado al competencia en exclusiva para determinar los contenidos básicos del régimen estatutario de los funcionarios, con el fin de que su definición conduzca a una regulación generalizada y uniforme para todo el conjunto de las Administraciones Públicas - y esto es lo que escrupulosamente pretende respetar la Sentencia del Tribunal Superior-, no debemos detenernos en tal precepto. Ello nos abocaría hacia una visión sesgada y parcial del tema, como a nuestro juicio le ocurre al Tribunal. De anverso, un más vasto y completo panorama resultaría de la interpretación sistemática y teleológica del art. 149.1.18 conectándolo con el art. 103.3 C.E., del que se desprende el marco normativo regulador del estatuto funcionarial.

\subsection{Reserva de ley y bases del régimen estatutario de los funcio- narios. Una nota sobre el contenido esencial del derecho de libertad sindical}

El art. 103.3 C.E. remite a la ley la regulación del estatuto de la Función Pública. Con esta reserva de ley, la Constitución consagra, aparentemente, el modelo tradicional autoritario de la función pública y la tendencia a la legalización de la disciplina de la relación funcionarial, configurando una minuciosa normación de los derechos, deberes

27 En un afán de síntesis, citaremos los preceptos más trascendentes conectados a nuestro estudio: art. 1, 23, 28, 37, 103, 149... entre otros. 
y situación jurídica del empleado público, con el fin de constituir una garantía precisa frente a la posible discrecionalidad de la Administración 28.

La referencia constitucional al estatuto de los funcionarios refleja así, una concepción tradicional del «Droit Administratif», cual es la regulación legal de la relación funcionarial; un importante paso en la contribución a lo que gráficamente GARCIA DE ENTERRIA llamó "lucha contra las inmunidades del poder administrativo". Se produce en este campo de estudio un reforzamiento singular del principio de legalidad, pues no basta la interdicción de la arbitrariedad, desviación de poder y justiciabilidad del poder administrativo, sino que también se requiere una restricción del poder reglamentario, mediante la intervención de la ley formal en la regulación de la situación del funcionario.

Pero si bien, en principio, es a este modelo al que parece responder el art. 103.3 C.E, debemos matizar esta significación, desde el momento en que, a renglón seguido, se reconoce también al funcionario un derecho a la sindicación, aunque sea con "peculiaridades", que por otro lado siempre deberán interpretarse restrictivamente para no anular la efectividad de esos derechos sindicales de los que trae causa la singularidad y que se consagran con carácter general en el art. 28 C.E. y especificamente para los funcionarios en el art. 103.3 C.E.

Por tanto, y como observa SANCHEZ MORON 29, tales peculiaridades tienen unos límites ínsitos en la propia Constitución, pues «en primer lugar sólo son admisibles si tienen por objeto garantizar el correcto funcionamiento de la Administración conforme a los principios de legalidad, eficacia, jerarquía, imparcialidad, etc., en caso contrario, el legislador incurriría en desviación de poder; en segundo lugar no pueden afectar al contenido esencial del derecho de sindicación».

Llegados a este punto nos surge un nuevo interrogante, pues ¿cuál es el contenido esencial del derecho fundamental consagrado en el art. 28.1 C.E.? La primera dificultad viene dada por la propia dicción del precepto, que contempla la libertad sindical como un derecho puramente organizativo: se reconoce el derecho de crear, afiliarse o no afiliarse a un sindicato, y de éste, de crear o afiliarse a confederaciones nacionales u organizaciones internacionales. Pero esta cláusula general se encuentra

28 En el mismo sentido se pronuncia RODRIGUEZ PIÑERO, en su artículo «La negociación colectiva de los funcionarios públicos en la Ley 9/87", La Ley, Relaciones Laborales, n. ${ }^{\circ} 20,1987$.

29 SANCHEZ MORON, op. cit., pp. 678 y ss. 
JURISPRUDENCIA

condicionada para dos colectivos, las Fuerzas o Institutos armados o Cuerpos sometidos a disciplina militar, a los que la ley podrá limitar o exceptuar el ejercicio del derecho, y los funcionarios, para los que la ley deberá regular las peculiaridades de su ejercicio. Nos encontramos por tanto ante un derecho fundamental con tres posibles contenidos, pero, y aquí nos surge el segundo interrogante, ¿el contenido esencial de la libertad sindical es, o mejor dicho, puede ser también tripartito? La respuesta vendrá de la mano del Tribunal Constitucional, pues es a él en definitiva al que corresponde precisar la naturaleza, alcance y determinación del contenido esencial de los derechos fundamentales.

Partiendo del concepto acuñado en STC 11/1981, de 8 de abril, este contenido esencial en el derecho de libertad sindical está integrado por aquellos derechos o facultades que identifican o hacen que sea recognoscible el ejercicio del mismo, o también, por aquella parte del contenido que es ineludiblemente necesaria para que el derecho permita a su titular la satisfacción de aquellos intereses para cuya consecución el derecho de libertad sindical se otorga. Sentadas estas premisas, el discurso del Tribunal Constitucional se ha encaminado a delimitar si los diversos derechos de actividad reconocidos para los sindicatos se integrarían en este contenido mínimo indestructible. De su doctrina podríamos extraer las siguientes conclusiones: «El derecho de libre sindicación que consagra el art. 28.1 C.E... es un derecho a llevar a cabo una libre acción sindical y, por consiguiente, el conjunto de actos que dentro de dicha expresión pueden encuadrarse» (STC 51/1984, de 25 de abril), y considerando que la acción sindical debe ser entendida como "actividad dirigida a la representación y defensa de los intereses de los trabajadores" (STC 118/1983, de 13 de diciembre), se puede afirmar que el art. 28 C.E. al reconocer la libertad sindical está admitiendo, "por la necesaria remisión al art. 7 C.E., del que aquél es interdependiente, el derecho de los sindicatos a actuar libremente para la defensa y promoción de los intereses económicos y sociales que les son propios, permitiendo así que la propia actividad del sindicato, como elemento teleológico que forma parte del contenido esencial de libertad sindical, se integre en el art. 28.1 C.E... La acción sindical comprende el derecho a que los sindicatos realicen las funciones que de ellos es dable esperar, entre las cuales se encuentra la negociación colectiva, la huelga y la incoacción de conflictos colectivos... de esta forma el art. 37.1 C.E. se conjuga en el art. 37.2 y con el art. 28 para definir el ámbito de ejercicio de la libertad sindical" (STC 37/1983, de 11 de mayo) ${ }^{30}$.

30 Es reiterada la doctrina del Tribunal Constitucional en este sentido: SSTC 39/1986, de 31 de marzo, 104/1987, de 17 de junio, 194/1987, de 8 de noviembre, 9/1988, de 25 de enero, 51/1988, de 22 de marzo, entre otras. 
Si bien ésta es la lógica mantenida por el Tribunal Constitucional y por la mayoría de la doctrina 31 , nos encontramos con una fisura de índole subjetiva en la negación de estos derechos de acción colectiva a los funcionarios públicos, especialmente manifestada en la Sentencia 57/1982, de 27 de julio: "Del derecho de sindicación de los funcionarios no deriva como consecuencia necesaria la negociación colectiva y menos todavía con efectos vinculantes, porque no existe un racional nexo causal que conduzca con exclusividad a aquellas consecuencias, al no ser obligado en lógica y en derecho que de la agrupación de los funcionarios en defensa de sus intereses, derive como única solución el celebrar un convenio obligatorio». Y el Tribunal, seguidamente y para apoyo de esta tesis continúa: "El ejercicio por los funcionarios públicos del derecho de sindicación ofrece ciertas peculiaridades a las que expresamente hace referencia la Constitución en sus arts. 28.1 y 103.3. Sin necesidad de entrar en el análisis de cuales puedan ser estas peculiaridades y en qué medida puedan afectar al contenido no esencial de este derecho, ya que solo al legislador estatal corresponde su determinación, pues, de una parte, implica la regulación o desarrollo de un derecho fundamental, en términos que aseguren la igualdad de su ejercicio, y de otra, forman parte del régimen jurídico de las Administraciones Públicas y del régimen estatutario de los funcionarios públicos».

El Tribunal juega por tanto con dos verdades, allí donde sólo puede haber una, con dos contenidos esenciales de un mismo derecho, lo que no nos parece ni ajustado al cabal entendimiento de este concepto jurídico, ni a la doctrina del Tribunal, que como ya dijimos, es punto de referencia en cuanto a la formulación de su significado. Se ha producido así una ambigüedad, que si bien superada por la realidad - no hace falta más que recordar la promulgación de la Ley 7/1990 de 19 de julio, de negociación colectiva de los empleados públicos-, no deja de inquietar, por las importantes consecuencias a que pudiera llevar en orden a la plena efectividad de la libertad sindical para el colectivo funcionarial. Y no es en vano lo que decimos, pues el no admitir la negociación como contenido sine qua non de la libertad en cuestión, podría llevar a la negación de esta posibilidad de determinar sus condiciones de trabajo, hecho que probablemente no sucederá, pero que con esta sentencia en la mano sería factible, y esos es lo preocupante. Es

31 En sentido opuesto a la inclusión de estos derechos de acción en el núcleo esencial del derecho de sindicación, especialmente crítico es OJEDA AVILES, A. «Un contenido esencial algo venial. $\mathrm{O}$ los problemas técnicos de una dispersión hermenéutica" $\left(R E D T, \mathrm{n}\right.$. $^{\circ}$ 44 , octubre-diciembre 1990). "Como contenido esencial del derecho de libre sindicación se encuentran la autonomía organizativa, la capacidad de obrar común y las libertades cívicas reconocidas a los individuos y a los grupos en que se integran. Más allá de eso comienzan los contenidos adicionales o no vinculantes para el legislador, y en especial toda la promoting legislation residente en la Ley Orgánica de Libertad Sindical. 
JURISPRUDENCIA

cierto, como también observa la Sentencia, que este derecho ofrece ciertas peculiaridades para los funcionarios, pero esto es una cosa y otra muy distinta sería restringirlo hasta tal punto que sólo se garantizara su vertiente individual - como derecho a fundar sindicatos o afiliarse al de su elección así como el de no sindicarse o no afiliarse-, pues ¿qué virtualidad tendría para el funcionariado este derecho, si se le niega en su parte más operativa, la de realizar las funciones que de los sindicatos es dable esperar en un Estado democrático de derecho?

Por tanto, peculiaridades, sí, pero siempre con respecto al contenido esencial del derecho a la libertad sindical, núcleo mínimo inviolable e indisponible, y que sería el mismo para ambos colectivos, funcionarios y trabajadores, y por tanto abarcaría la negociación colectiva, como uno de los medios primordiales de acción del sindicato. Además dos razones adicionales apoyarían nuestra tesis: por una parte, que el común de las sentencias constitucionales defensoras de la inclusión de la negociación en el núcleo duro del derecho no hacen distingos sobre los sindicatos a que se refiere, y por otra, que en modo alguno la lectura de la Constitución nos lleva a la exclusión de este derecho para el empleado público, cosa que sí sería posible para las Fuerzas o institutos armados o demás cuerpos sometidos a disciplina militar, en que el propio art. 28 C.E., ya prevé la limitación o privación del derecho 32 .

Parece entonces que lo realmente importante será definir cuales deben ser las peculiaridades en el ejercicio del derecho en cuestión, para que quede a salvo el contenido esencial de la libertad sindical, o más en concreto cuál es el contenido ineludiblemente necesario que permita a su titular la satisfacción de los intereses para cuya consecución el derecho se le otorgó. Y este es, en definitiva, el objetivo de este trabajo, dar las pautas para que no se rebase es contenido esencial, cosa que sucedería si «el derecho quedase sometido a limitaciones que lo hacen impracticable, lo dificultan más allá de lo razonable o lo despojan de la necesaria protección» 33 .

Como bien sabemos, una de las peculiaridades que afectan al contenido de la relación funcionarial es la reserva de ley prevista en el art. 103.3 C.E., que debe ser interpretada, en la linea perfilada por la doctrina del Constitucional ${ }^{34}$, en los siguientes términos. La reserva de ley

\footnotetext{
32 Así vemos en una primera lectura del precepto la diferente intensidad con que el constituyente se refiere a estos cuerpos "La ley podrá limitar o exceptuar el ejercicio de este derecho", y al funcionariado, en que simplemente se refiere a que "la ley regulará las peculiaridades de su ejercicion.
}

33 STC $11 / 1981$, de 8 de abril.

34 En especial, doctrina sentada en la STC 99/87 de 11 de junio. 
implica, primero, que la ley debe contener una determinación material suficiente de los ámbitos incluidos en el Estatuto de los funcionarios, consignando al Reglamento un papel limitado y subordinado en la regulación funcionarial, y desde otro punto de vista, que la reserva tiende a eliminar el poder de disposición unilateral de la Administración, sin que suponga necesariamente una exclusión total de la posibilidad de autonomía colectiva en el seno de la función pública. Por tanto, en el ámbito reservado por la Constitución a la ley, no es imposible una intervención auxiliar o complementaria del reglamento, pero siempre que esa remisión restrinja efectivamente el ejercicio de la potestad reglamentaria a un complemento de la regulación legal, que sea indispensable por motivos técnicos o para optimizar el cumplimiento de los fines constitucionales o los de la propia ley, pero sin llegar a una total abdicación por parte del legislador, de su facultad para establecer reglas limitativas, transfiriendo esta facultad al titular de la potestad reglamentaria.

Trasladando esta doctrina, compartimos la opinión de Blasco Esteve ${ }^{35}$, en cuanto a que «la regulación legal no tiene porqué ser exhaustiva y el propio estatuto puede dejar espacios temáticos sin cubrir, remitiendo su determinación a la negociación de las partes». De esta forma se daría cumplimiento a dos mandatos constitucionales: el del art. 103.1 y el del 28.1 C.E. Y ésta es la primera conexión de relevancia a la hora de enjuiciar el tema que estudiamos.

En cuanto al art. 149.1.18 C.E, que se expresa en los siguientes términos: «El Estado tiene competencia exclusiva ...sobre la bases del régimen jurídico de las Administraciones públicas y del régimen estatutario de sus funcionarios, que en todo caso, garantizarán a los administrados un tratamiento común ante ellas...», a nuestro entender, no es éste el precepto clave para la resolución del recurso planteado, solución que es a la que parece acogerse el Tribunal, reduciendo a un mero problema competencial el fondo de la controversia.

Lo primero que cabe observar es, como ya ha precisado una abundante jurisprudencia constitucional 36 , que "el uso sistemático de los términos legislación y legislación básica que se hace por el art. 149 C.E. en sus distintos apartados, no pretende reservar a la ley las materias a que se refieren, sino solo distribuir entre el Estado y las Comunidades

35 BLASCO ESTEVE, «La negociación colectiva de los funcionarios públicos», REDA, $\mathrm{n}$. 52 , p. 545.

36 STC $86 / 82$ de 26 de enero, $91 / 84$ de 9 de octubre, 25/83 de 7 de abril, $76 / 83$ de 5 de agosto, $99 / 87$ de 11 de junio... entre otras. 
Autónomas los poderes normativos (legislativos o reglamentarios, según proceda), correspondientes a cada una de dichas instancias".

Por ello, cuando el art. 149.1.18 C.E. define la competencia exclusiva del Estado para establecer las bases del régimen estatutario de los funcionarios, lo que trata de enunciar es una competencia normativa estatal que no agota la regulación de la materia, sino que prevé una ulterior participación de las Comunidades Autónomas en tal regulación, mediante normas de desarrollo. "Lo que la C.E. persigue es que tales bases tengan una regulación normativa uniforme y de vigencia en toda la nación, que asegure en aras de intereses generales superiores a los de cada Comunidad, un común denominador normativo, un mínimo común, a partir del cual cada una podrá establecer las peculiaridades que le convengan».

Al hilo de nuestra argumentación, y siguiendo a la doctrina más autorizada 37 , la función propia de la legislación básica a que se refiere el apdo. 18 del art. 149.1 C.E., es la de delimitar el campo legislativo autonómico, lo que no supone exclusión o vaciamiento de sus competencias, sino obligación de atenerse en el ejercicio de éstas, al sentido, amplitud y fines de la materia básica, que las Comunidades Autónomas deben respetar ${ }^{38}$.

\section{UNA BREVE NOTICIA SOBRE LA LEY 7/90 DE 19 DE JULIO SOBRE NEGOCIACION COLECTIVA Y PARTICIPACION DE LAS CONDICIONES DE TRABAJO DE LOS EMPLEADOS PU- BLICOS}

Durante la elaboración de este trabajo, se fue gestando un nuevo marco normativo, instaurado por la Ley $7 / 90$ de 19 de julio, sobre negociación colectiva y participación en la determinación de las condiciones de trabajo de los empleados públicos, que ha confirmado con creces nuestra particular visión del tema negocial, demostrando la criticable parquedad con que se ha venido concibiendo la negociación colectiva de los funcionarios en nuestro Derecho, configurada en un modelo de

37 CAMARA DEL PORTILLO, "La función pública ante el Tribunal Constitucional, una oportunidad perdida», REDA 57, 1988; PIÑAR MAÑAS, "Las estructuras de participación y representación del personal al servicio de las Administraciones públicas", REDA $65,1988$.

38 La Exposición de Motivos de la Ley $9 / 87$ reitera esta idea: «La ley pretende conjugar el principio de competencia exclusiva del Estado para determinar las bases del régimen jurídico de las Administraciones y el régimen estatutario de sus funcionarios, con la potestad autoorganizatoria de las Comunidades Autónomas". 
contemplación restrictiva y harto peculiar en la precedente Ley $9 / 87$, y que se ha visto reflejada en la Sentencia. Con todo, la nueva normativa debe ser examinada con cuidado, pues en algunas cuestiones habrá que entenderla en sus justos términos, siempre teniendo presentes ciertas particularidades de la negociación en el ámbito de la función pública, que parece haber obviado, en pro del consenso, la Ley 7/1990.

La nueva ley tiene su origen, como pone de relieve su propio Preámbulo, en el Acuerdo suscrito por el Gobierno y los sindicatos de mayor representación a nivel estatal el día 1 de febrero de 1990. Como bien observa Escudero ${ }^{39}$, se está ante una "norma fruto de un acuerdo previo entre determinados interlocutores sociales y los poderes públicos».

La innovación más significativa, a nuestro juicio, es la modificación del art. 32 de la Ley 9/87, relativo al contenido de la negociación, que enriquece cualitativa y cuantitativamente su ámbito material a los siguientes aspectos:

- incremento retributivo de los funcionarios públicos y del personal estatutario de las Administraciones públicas que proceda incluir en el Proyecto de presupuestos Generales del Estado o, para su respectivo personal, en los proyectos normativos correspondientes de ámbito autonómico y local.

- la determinación de los programas y fondos para la acción de promoción interna, formación y perfeccionamiento.

- la determinación de las prestaciones y pensiones de las clases pasivas, y en general, todas las materias relacionadas, de algún modo, con la mejora de las condiciones de vida de los funcionarios jubilados.

- las propuestas sobre derechos sindicales y de participación.

— las medidas sobre salud laboral.

- todas las materias que afecten de algún modo al acceso a la función pública, carrera administrativa, retribuciones y Seguridad Social o a las condiciones de trabajo de los funcionarios y cuya regulación exija norma con rango de ley.

39 RICARDO ESCUDERO, "Comentario: el nuevo marco de la negociación colectiva de los funcionarios públicos. Novedades en materia de elecciones a órganos de representación unitaria». La ley, n. ${ }^{\circ} 19$, octubre 1990 , pp. 89 y ss. 
JURISPRUDENCIA

El análisis de las novedades, especialmente en materia económica, revela el elogiable avance de la ley respecto a la patente cicatería a que quedaba reducida la negociación, pues - queremos o no- una verdadera negociación exige imprescindiblemente discutir las variables retributivas y aquellas que tienen una traducción económica, ya sea inmediata o mediata.

En cualquier caso, debemos tener presente que la inclusión de una materia como negociable, no quiere decir que todo lo relacionado con la misma pertenezca exclusiva y excluyentemente al ámbito de la negociación colectiva, de forma que se produzca un vaciamiento total de la postestad unilateral de regulación del Estado. Muy al contrario, la reserva de ley del art. 103 C.E. y la especificación que sobre el régimen estatutario contiene la LMFP y que ha sido definido por el Tribunal Constitucional, va a afectar a todas y cada una de estas materias enunciadas en el nuevo art. 32 -como sucedía con el antiguo-. En consecuencia habrá muchos aspectos que estarán predeterminados por la ley, sin que ello signifique que exista una reserva absoluta, pues en ese caso el precepto carecería de sentido, sino que en ellas la negociación solo podrá intervenir en aspectos más secundarios, y cuando ello le sea permitido, de una forma u otra, por la propia ley. Así, hay que replantear la potestad unilateral de la Administración, dejando un «espacio vital para el convenio", al que en muchos casos le corresponderá una competencia más de detalle, de especificación de puntos abordados por la ley, y en otros casos de ordenación de cuestiones no tratadas por ésta 40 . No estaría de más recordar que la reserva se extiende, generalmente, a los deberes y derechos mínimos de los funcionarios, así como a la relación que se ha llamado orgánica —derivada de las potestades de organización de la Administración-, con el problema añadido de la indeterminación y la amplitud del concepto de organización ${ }^{41}$. Especial precaución merecen algunos apartados del nuevo art. 32 , sobre todo la posibilidad de abrir a la negociación los sistemas de ingreso en la función pública -en que ya no habrá que estar tan sólo a la reserva de ley, sino al respeto de unos principios constitucionales, como el de igualdad, mérito y capacidad previstos en el art. 23 C.E.-,

40 DEL REY GUANTER, S. Comentarios a la Ley de Organos de representación, determinación de las condiciones de trabajo y participación del personal al servicio de las Administraciones Públicas, MAP, Madrid, 1988.

41 Aunque como señala ORTEGA ALVAREZ, L., estas dificultades de interpretación en cuanto al circulo conceptual del término, han sido salvadas por los pactos políticos entre Gobierno y sindicatos a la hora de elaborar la legislación sobre negociación colectiva, senalando las materias específicas sobre las que puede versar un convenio o eliminando determinados conceptos de la materia negocial. Manual de Derecho Administrativo, Ariel, Barcelona, 1990, p. 440. 
la preparación de los planes de oferta de empleo público, que hay que entender en sus justos términos y además está condicionada de modo importante por los Presupuestos Generales del Estado para el periodo correspondiente, incluso las propuestas sobre derechos sindicales y de participación, también condicionadas por la reserva constitucional del art. 28 C.E.

Como conclusión a este trabajo, nos parecen especialmente interesantes las propuestas sobre un marco común que podría desarrollarse en Europa en relación a la negociación colectiva, ahora que estamos en la linea evolutiva que nos lleva cada vez más a la contractualización de la relación de empleo público, y que han sido recientemente expuestas por Luis Ortega 42:

En primer lugar debería existir un nivel de funcionarios que asuman el desarrollo de la función negocial, desligados de cualquier actividad sindical.

En segundo, el derecho de negociación debería limitarse a imponer a la Administración el deber jurídico de abrir negociaciones antes de la elaboración de los planes presupuestarios. Si se obtuviese el acuerdo habría que deslindar aquello constitucionalmente reservado a la ley.

Los convenios tendrían plena eficacia entre las partes y su vulneración podría ser objeto de denuncia ante los Tribunales.

42 ORTEGA ALVAREZ, L. PAREJO ALFONSO, L., JIMENEZ BLANCO, A., op. cit., p. 442. 